\title{
On the improvement of sea-ice models for climate simulations: the Sea Ice Model Intercomparison Project
}

\author{
Peter Lemke, ${ }^{1}$ W. D.Hibler, ${ }^{2}$ G. Flato ${ }^{3}$ M. Harder, ${ }^{4}$ M. Kreyscher ${ }^{4}$ \\ ${ }^{1}$ Institut für Meereskunde, D-24105 Kiel, Germany \\ ${ }^{2}$ Thayer School of Engineering, Dartmouth College, Hanover, NH 03755, U.S.A. \\ ${ }^{3}$ Canadian Centre for Climate Modelling and Analysis, Atmospheric Environment Service, \\ University of Victoria, Victoria, British Columbia U8W 212, Canada \\ ${ }^{4}$ Alfred-Wegener-Institut für Polar-und Meersforschung, D-27570 Bremerhaven, Germany
}

\begin{abstract}
Experiments with dynamic thermodynamic sea-ice models indicate a strong dependence of the net freezing rate, sea-ice transport and variability on dynamic model parameters. Although current dynamic-thermodynamic sea-ice models show relatively good agreement with observations, an optimization seems to be necessary, especially for the parameterizations of dynamic processes.

Presently, only a few coupled climate models use dynamic thermodynamic sea-ice models. In order to promote, by means of coordinated numerical experiments, the development of an optimal sea-ice model for climate research, the Sea Ice Ocean Modelling Panel of the Arctic Climate System Study (ACSYS, a project of the World Climate Research Programme) has initiated the Sea Ice Model Intercomparison Project (SIMIP). The first results from this model hierarchy approach are presented.
\end{abstract}

\section{INTRODUCTION}

The polar oceans with their sea-ice cover have received attention recently for two reasons. Firstly, the global conveyor-belt circulation of the ocean is believed to be forced in the North and South Atlantic through deep-water formation. Sea-ice export to lower latitudes plays a major role in the intensity of this forcing mechanism. Secondly, $\mathrm{CO}_{2}$ response experiments with coupled atmosphere ocean circulation models show an enhanced warming in polar regions for increased atmospheric greenhouse gases. Whether this is due to real physical feedback processes or to unrealistic simplifications of the sea-ice model component remains to be determined. Coupled climate models generally use thermodynamic sea-ice models or sea-ice models with simplified advection schemes.

The importance of the role of sea ice in the climate system calls for an improved representation of sea ice in global climate models. The use of more sophisticated dynamic thermodynamic sea-ice models is required because dynamic-thermodynamic sea-ice models appear to be less sensitive to global warming than pure thermodynamic models, and, secondly, only dynamic -thermodynamic sea-ice models provide the fresh-water/salt flux (net freezing rate) associated with the ice motion.

The net freezing rate, as well as the sea-ice export out of Fram Strait, exhibit a large variability, indicating the importance of the moving sea-ice cover. Presently only a few coupled general circulation models (GCMs) use realistic sea-ice components (i.e. the oceanic surface buoyancy flux is not realistic in most climate simulations). The pronounced pattern of the net freezing rate with fresh-water fluxes of the order of the annual precipitation, or even larger, is not reproduced in most models.

In order to improve this situation the Sea Ice Ocean Modelling (SIOM) Panel of the Arctic Climate System Study (ACSYS) has been charged with the task of determining the optimal sea-ice component for use in coupled climate models. This task is the main focus of the Sea Ice Model Intercomparison Project (SIMIP), and includes two work packages: to produce a standard forcing and verification dataset, and to apply a model hierarchy from which the optimal model is derived through minimization of an error function that measures the deviation between model and observations.

The pattern of the net freezing rate depends mainly on the structure of the wind field and the dynamic model parameters. Thermodynamic processes can modify the freezing rates, but the effect is limited, since the freezing rates are smaller for thicker ice. Therefore, during the first phase of the model optimization, the investigations are focused on the dynamical part of the sea-ice model, but thermodynamic parameterizations will be treated as soon as possible.

\section{MODEL DOMAIN AND FORGING DATA}

The prognostic equations are solved on a rotated spherical grid (with the model pole on the equator in the Indian Ocean) for the whole Arctic with a resolution of $1 \times 1^{\circ}$ and a daily time-step. Atmospheric forcing data are available from the European Centre for Medium-Range Weather Forecasting (ECMWF) for 1986-92. The ECMWF $10 \mathrm{~m}$ wind field is averaged to 24 hour means. ECMWF $2 \mathrm{~m}$ air temperatures and dew-point temperatures over ice-covered regions are dominated by prescribed monthly climatologi- 
cal surface temperatures, and show almost no variability except for the large steps at the end of each month. To smooth these step functions and to remove the difference of $2^{\circ} \mathrm{C}$ in the summer air temperatures for different years due to changes in the ECMWF model (in recent years the temperature of melting sea ice has been set to the freezing point of sea water instead of to $\left.0^{\circ} \mathrm{C}\right), 7$ year mean temperatures are derived for each month, and the model is forced with temperatures linearly interpolated between these monthly means. Since in summer the 7 year monthly mean ECMWF air temperatures are still below the observed average temperature of $0^{\circ} \mathrm{C}$ in the central Arctic, a lower limit for the air temperatures of $0^{\circ} \mathrm{C}$ is imposed for 15 June to 15 August as an additional correction. Dew-point temperatures are modified accordingly, so that the relative humidities are preserved. Cloudiness (Ebert and Curry, 1993) and precipitation (Vowinkel and Orvig, 1970) are prescribed as spatially constant climatological monthly means.

The ocean is represented rather crudely by a motionless, $50 \mathrm{~m}$ deep mixed layer. Horizontal heat transport and vertical mixing are represented by specifying a spatially varying, annual average heat flux into the underside of this mixed layer. Likewise, input of momentum from the ocean into the ice is accomplished by specifying a spatially varying, annual average geostrophic current field. Geostrophic currents and sea-surface tilt are taken from an oceanic circulation model (Gerdes and Köberle, 1995). The oceanic heat flux into the upper mixed layer of fixed depth is prescribed from a coupled sea-ice-ocean circulation model (Hibler and Zhang, 1993).

\section{SEA-ICE MODEL INTERCOMPARISON}

In order to derive the optimal description of the sea-ice physics, high priority is placed within the modelling program on sensitivity experiments running different sea-ice model parameterizations on the same spatial grid with the same forcing, initial values and verification data. These studies investigate the open questions concerning the dynamics and thermodynamics of sea ice:

(1) How many ice-thickness categories have to be resolved by the model?

(2) What is the optimal constitutive law?

(3) Which shape of the yield curve is realistic?

(4) What strength parameterization is appropriate?

(5) What is the optimal albedo parameterization, including the dependence on melt ponds, ice thickness, snow cover and snow temperature?

(6) How is the absorbed insolation disposed and how does it affect ice thickness and concentration (lead amount), including melting of the top, bottom or side surface of the ice, heating of the ice, enlargement of brine pockets, storage in leads and storage in the mixed layer beneath the ice?

The optimal model is determined from a model hierarchy concerning dynamics, thermodynamics and numerics using the same forcing data derived from the analyses of the ECMWF, and comparing the results with buoy trajectories and ice-thickness observations as verification data.

A variety of different yield curves may be investigated by using the viscous plastic rheology. Based on previous investigations (Hibler, 1979; Owens and Lemke, 1990; Ip and others, 1991) the most physically realistic yield curves have moderate amounts of shear strength and some type of closure, so that there is no outward pressure in the absence of deformation. Consequently the main candidates for model intercomparison would be the ellipse with replacement (i.e. the pressure taken to be a function of deformation rate so that it goes to zero in the limit of small strain rates) and the truncated ellipse that is similar except that it has no tensile strength. However, within this constraint there are still issues about what the optimal wind and water drag coefficients should be, and how these parameters should vary with time. Also, what is the optimal strength constant and how should the strength be parameterized as a function of ice-thickness characteristics?

With respect to simpler models that may be particularly useful in climate studies, especially when monthly mean or otherwise smoothed forcing fields are used to drive an ice model, some variation of a cavitating fluid seems most useful. The cavitating fluid approximation neglects shear and tensile strength and retains only compressive strength. One formulation of the cavitating fluid is the iterative solution of Flato and Hibler (1992), which provides a precise value for the ice pressure. This iteration procedure typically begins from a free-drift velocity field that is then modified to prevent excessive ice-thickness buildup in a momentum conserving way.

Another simplified model is to make use of constant bulk and shear viscosities, even though this will lead to tensile stresses. However, an additional problem here is that values of these viscosities large enough to restrict the ice-thickness buildup will prevent slippage and ice flow near the coast that occurs in plastic systems with the viscosities taken to be nonlinear functions of the deformation-rate invariants. The limitations of this type of model can however be tested in a model intercomparison study.

Compressive strength is a fundamental material property of pack ice that must be parameterized in a model. The standard parameterization used in two-level ice models is (Hibler, 1979):

$$
P=P^{\star} h \exp [-K(1-A)]
$$

where $P$ is the two-dimensional (2-D) compressive strength $\left(\mathrm{N} \mathrm{m}^{-1}\right), P^{\star}$ is a strength parameter $\left(\mathrm{N} \mathrm{m}^{-2}\right), h$ is the mean ice thickness $(\mathrm{m}), K$ is a dimensionless strength parameter, and $A$ is the sea-ice concentration. $P^{\star}$ essentially determines the strength, whereas $K$ controls the decay of ice strength with decreasing concentration. The value of $P^{\star}$ has been inferred by comparison of modelled and observed buoy drift (Hibler and Walsh, 1982; Flato and Hibler, 1992). Flato (1994) compared this strength parameterization to that proposed by Rothrock (1975) based on ridging energy losses in a model that explicitly treats the redistribution of ice thickness by ridging. Flato (1994) noted that there was considerable variability in the resulting ice strength, and that alternative parameterizations based on, for example, mean thickness squared, ought to be considered. These will be investigated in this project.

The open questions concerning the thermodynamic processes are the proper albedo parameterization, the treatment of melt ponds, and snow cover. Furthermore, it is not settled how the absorbed insolation is disposed, and how it affects the ice concentration. Similarly, an improved flux 
parameterization is needed for the radiative and turbulent fluxes. Here the question arises as to whether the energy balance should be calculated for ice and ocean separately, or as a function of ice concentration.

\section{MODEL HIERARGHY}

\section{Prerequisites:}

(1) Model grid: all models will use the same grid and landboundary mask.

(2) Advection algorithm: all models will use a simple upstream-differencing advection scheme.

(3) Thermodynamic model: all models will use the same surface-energy budget and albedo parameterizations, and will compute thermodynamic growth assuming a linear temperature profile. Thermodynamic calculations will be performed separately for open water and seven thickness categories, assuming a uniform distribution of ice thickness between zero and twice the mean ice thickness.

(4) Snow model: all models will use the same snow model in which snow mass per unit area evolves according to a conservation equation, but heat conduction through the ice/snow slab is computed assuming a linear temperature profile and a conductivity obtained as a weighted mean of ice and snow conductivities. An improvement of the heat conduction model is envisaged at a later stage by implementing a consistent three-layer Semtner code (1976).

(5) Mixed layer: all models will include a motionless, fixeddepth mixed layer ( $50 \mathrm{~m}$ deep), which is used to store heat during the ice-free season. Only when the mixed layer cools to freezing point $(271.2 \mathrm{~K})$, is ice allowed to form.

(6) Atmospheric forcing and oceanic boundary conditions: all models will make use of the same atmospheric forcing fields and parameterizations of radiative fluxes. The models will also use specified annual mean ocean geostrophic currents and heat fluxes into the underside of the mixed layer.

(7) Initial conditions and integration: all models will begin with an ice-free ocean, perform a 7 year spin-up, the end of which is used as the initial condition for a subsequent 7 year analysis run. The 7 year period is 1986-92.

Several ice-dynamics schemes will be compared in this project. Each model will be optimized by adjusting both the surface wind drag coefficient and the strength parameters $P^{\star}$ and $K$ so as to achieve the best fit to observed buoy drift. The specific models to be compared are as follows (a more detailed description is provided in Kreyscher and others, 1997): (1) viscous plastic with replacement closure, elliptical yield curve; (2) viscous plastic with replacement closure, truncated elliptical yield curve; (3) viscous-plastic with zero shear viscosity; (4) cavitating fluid; (5) compressible Newtonian fluid (constant $\eta$ and $\zeta$ ); and (6) surface current drift with step-function stoppage.

The initial focus of this project is on sea-ice dynamics. However dynamics and thermodynamics are closely coupled through the ice-strength parameterization. The thermodynamic parameters that control the partitioning of net surface energy flux between lateral and vertical growth or melt are particularly important because of the exponential dependence of strength on compactness. This includes the parameterization of the thermodynamic source-term $S_{A}$ (Hibler, 1979) in the balance equation for the ice concentration and the inclusion of the three-layer Semtner (1976) model for the heat conduction through the ice. These parameters will also be optimized in the second phase of the project, primarily based on comparison with SSM/I-derived ice concentration.

\section{VERIFICATION DATA AND OPTIMIZATION METHOD}

The main verification data for the model dynamics is the wealth of buoy drift data. These data can be compared with model results in various ways. One is to compare observed and modelled trajectories. Another is to compute drift speed over specified time intervals for both modelled and observed trajectories, and average these drift speeds (and directions) over various regions. Yet another comparison is to measure the distance or displacement between endpoints of the modelled and observed trajectories over some time interval (both trajectories having started at the same position at the beginning of the interval). The trajectory endpoint displacement is some combination of drift speed and direction discrepancies, and so is a useful single measure of the "goodness" of a modelled trajectory. Finally, one can select a region and compute the distribution of modelled and observed drift speeds. Results of such a comparison are shown in Figure 1 in the form of drift speed histograms for various sectors of the Arctic.

Another important dataset containing daily total ice concentration is available from the passive microwave sensors SMMR and SSM/I for the period under investigation. The ice concentrations are calculated with the NASA Team algorithm with a resolution of $25 \mathrm{~km}$. For comparison with the numerical simulation the SMMR and SSM/I data are interpolated to the model grid with a grid spacing of $110 \mathrm{~km}$. First results with the viscous-plastic model show a well-reproduced seasonal cycle of the ice extent not shown). Deviations are due to the lack of an interactive ocean model and the not-yet-tuned thermodynamic parameters. An optimal description of ice concentration will only be achieved after the second phase, when the thermodynamic code has been optimized.

Ice-thickness observations are not widely available, and most of the observations that are available are ice-draft measurements from submarine upward-looking sonar. The data available for the present project are seven $50-100 \mathrm{~km}$ transects across the North Pole as reported by McLaren and others (1994). For comparison to modelled thickness, these draft observations can be approximately converted to thickness by multiplying draft by the ocean/ice density ratio 1.12. The resulting mean thicknesses are compared to the model derived values (Kreyscher and others, 1997).

In order to ensure a fair comparison, and to provide the most suitable set of parameters for subsequent applications of the various models, each model will be optimized by adjusting various parameters to produce the best agreement with observations. Such an optimization procedure necessarily involves the definition of an error function that measures the goodness-of-fit between model and observations. It 

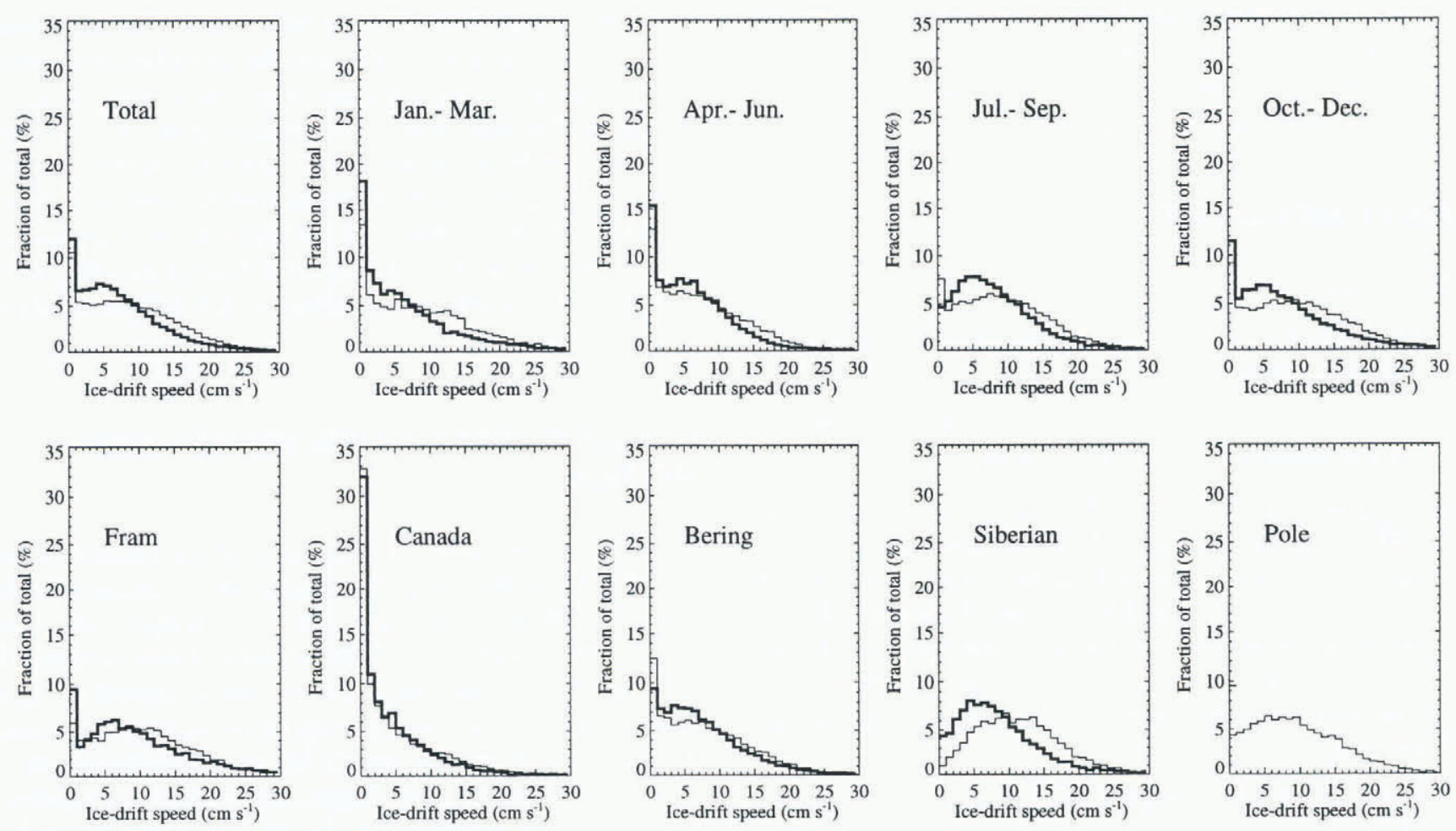

\begin{abstract}
Fig. 1. Observed (thick line) and simulated (thin line) daily speed distributions. The simulation results are obtained from the viscous-plastic model. Drift-speed statistics are calculated for four seasons January-March, April-June, July-September, October December. There are five separate regions: Fram, south of $85^{\circ} \mathrm{N}$, between $45^{\circ}$ Wand $45^{\circ} \mathrm{E}$; Canada, south of $85^{\circ} \mathcal{N}$, between $135^{\circ} \mathrm{W}$ and $45^{\circ} \mathrm{W}$; Bering, south of $85^{\circ} \mathcal{N}$, between $135^{\circ} \mathrm{W}$ and $135^{\circ} \mathrm{E}$; Siberia, south of $85^{\circ} \mathcal{N}$, between $135^{\circ}$ E and $45^{\circ} \mathrm{E}$; Pole, north of $85^{\circ} \mathrm{N}$ and for all data (Total).
\end{abstract}

is not obvious a priori how to define the best error function, and this will be the subject of more careful study during the early stages of the intercomparison project. Nevertheless, we can outline some of the candidate error functions that might be used, either singly or in combination. Ice-motion comparisons, based on observed buoy drift, will be most important for dynamic parameters like ice strength and drag coefficients. Some example error functions are therefore:

(1) Average trajectory endpoint displacement after some time interval (e.g. 10 days).

(2) Average drift-speed and direction differences computed over some time interval.

(3) Difference in shape of drift-speed histograms.

Ice-concentration comparisons, based on SMMR and SSM/I data, will be most important for thermodynamic parameters like those involved in partitioning between vertical and lateral growth and melt. Some examples of error functions in this case might be:

(1) Difference in concentration averaged over various regions and seasons.

(2) Difference in ice extent in various sectors (defined as the area enclosed by the $15 \%$ concentration contour).

Ice-thickness data will be treated similarly to ice concentration, although this dataset is significantly smaller. Certain of the above error functions may not be used in the definition of optimality, but may still be useful in comparing the behavior of various models. For example, differences between the optimal viscous-plastic model and optimal cavitating fluid model might be illustrated by comparing the shape of the drift-speed histograms (see Figs 1 and 2).

\section{FIRST RESULTS AND CONCLUSIONS}

During the first phase of SIMIP, four models have been compared: a viscous-plastic model based on Hibler (1979) with an elliptical yield curve and replacement closure; a cavitating fluid model (Flato and Hibler 1992); a compressible Newtonian fluid model; and a free-drift model with stoppage (for details see Kreyscher and others, 1997). All models have been optimized by minimizing an error function through tuning of the dynamic model parameters'. From the application of the different error functions discussed above it is obvious that the speed-distribution difference represents the most adequate error function for the optimization of dynamic model parameters.

This speed distribution is displayed in Figure $l$ as annual mean and seasonal averages for the whole Arctic (upper panel) and as annual mean for five selected regions (lower panel) for the viscous-plastic model (thin lines) and the buoy observations (thick lines). The viscous-plastic model represents the observations well, but certain differences are apparent.

The speed distributions of the competitive models are shown in Figure 2 for the Canada region (a) and for the Bering region (b). In the Canada region the viscous-plastic model yields the best results, whereas in the Bering area the

1 The cavitating fluid model has been implemented and optimized at the Canadian Centre for Climate Modelling and Analysis; the other models have been applied at the Alfred-Wegener-Institut. Special care has been taken to ensure the same treatment of all models through exchange of model and analysis codes. 

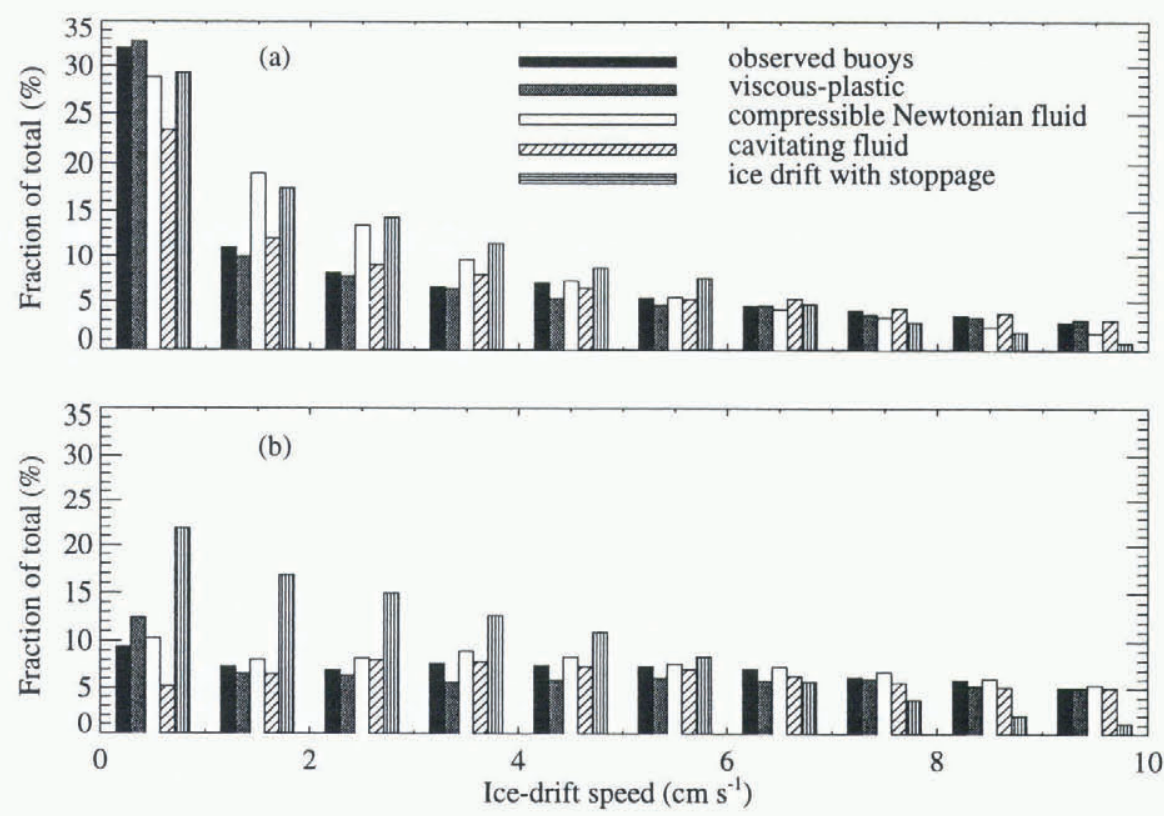

Fig. 2. Comparison of drift-speed distributions for the observations and four different dynamics schemes. Drift statistics are shown for (a) the Canada region (south of $85^{\circ} \mathcal{N}$, between $135^{\circ} \mathrm{W}$ and $45^{\circ} \mathrm{W}$ ) and (b) for the Bering region ( $50 u t h$ of $85^{\circ} \mathcal{N}$, between $135^{\circ}$ Wand $\left.135^{\circ} \mathrm{E}\right)$.

compressible Newtonian-fluid model performs best. Summed over all regions the viscous plastic model achieves the best fit. It is, therefore, at this stage considered to be the best representation of sea-ice dynamics in large-scale models. The simple free-drift model with stoppage significantly overestimates the small drift speeds, whereas the cavitating fluid underestimates the occurrence of low speeds, especially in the Bering region (for more details see Kreyscher and others, 1997). In conclusion, the viscousplastic model represents the best starting point for further model improvements.

\section{AGKNOWLEDGEMENTS}

The atmospheric forcing data were derived from ECMWF analyses.

\section{REFERENCES}

Ebert, E. E. and J.A. Curry. 1993. An intermediate one-dimensional thermodynamic sea ice model for investigating ice atmosphere interactions. f. Geophys. Res., 98 (C6), 10,085-10,109.

Flato, G. M. 1994. Parameterizing the strength of Arctic sea ice. In ACSYS Conference on the Dynamics of the Arctic Climate System, 7-10. November 1994, Gothenburg, Sweden. Proceedings. Geneva, World Meteorological Organisation, 278-282 (WCRP Report 94, WMO TD 760.

Flato, G. M. and W. D. Hibler, III. 1992. Modeling pack ice as a cavitating fluid. 7. Phys. Oceanogr. 22 6, $626-651$

Gerdes, R. and C. Köberle. 1995. Influence of DSOW in a numerical model of the North Atlantic general circulation. 7. Phys. Oceanogr, 25 (11), 2624-2642.

Hibler, W. D., III. 1979. A dynamic thermodynamic sea ice model. J. Phys. Oceanogr., 9 7, 815-846.

Hibler, W. D., III and J. E. Walsh. 1982. On modeling seasonal and interannual fluctuations of Arctic sea ice. 7. Phys. Oceanogr., 12 12), 1.514-1523.

Hibler, W. D., III and J. L. Zhang. 1993. Interannual and climatic charcteristics of an ice ocean circulation model. In Peltier, W. R., ed. Ice in the climate system. Berlin, etc., Springer-Verlag, 633-651. (NATO ASI Series I: Global Environmental Change 12.

Ip, C. F., W. D. Hibler, III and G. M. Flato, 1991. On the effect of rheology on seasonal sea-ice simulations. Ann. Glaciol., 15, 17-25.

Kreyscher, M., M. Harder and P. Lemke. 1997. First results of the Sea Ice Model Intercomparison Project (SIMIP). Ann. Glaciol. 25 (see paper in this volume.

McLaren, A. S., R. H. Bourke, J. E. Walsh and R. L. Weaver. 1994. Variability in sea-ice thickness over the North Pole from 1958 to 1992. In Johannessen, O. M., R. D. Muench and J. E. Overland, eds. The polar oceans and their role in shaping the global environment: the Nansen Centennial volume. Washington, DC, American Geophysical Union, 363 -371. Geophysical Monograph 85.

Owens, W. B. and P. Lemke. 1990. Sensitivity studies with a sea-ice mixed layer-pycnocline model in the Weddell Sea. J. Geophys. Res., 95 C6), $9527-9538$.

Rothrock, D. A. 1975. The energetics of the plastic deformation of pack ice by ridging. 7. Geophys. Res., 80 (33), 4514-4519.

Semtner, A. 1976. A model for the thermodynamic growth of sea ice in numerical investigations of climate. J. Phys. Oceanogr., 6 (5), $379-389$.

Vowinckel, E. and S. Orvig. 1970. The climate of the north polar basin. In Orvig, S., ed. Climates of the polar regions. New York, Elsevier, 129-252. (World Survey of Climatology 14. 